\title{
The silent spermatozoon: are man-made endocrine disruptors killing male fertility?
}

\author{
Bradley D Anawalt \\ Asian Journal of Andrology (2013) 15, 165-168; doi:10.1038/aja.2012.148; published online 21 January 2013
}

$I^{n}$ n 1992, a Danish group led by Skakkebaek reported in a meta-analysis that global mean sperm countswerefalling and that testicularcancer, hypospadias and cryptorchidism were increasing. They hypothesized that environmental factors were the cause. Their metaanalysis was criticized subsequently for many methodological flaws. However, their controversial meta-analysis and hypothesis spurred public and scientific interest in the study of male reproductive function and stimulated more rigorous scientific work in the area. Subsequent research has not convincingly supported their hypothesis. However, it is crucial to continue high quality studies of the effects of drugs and manmade pollutants on male reproductive function.

In 1962, Rachel Carson published her work 'A Silent Spring. ${ }^{1}$ The thesis of the book was that widespread use of pesticides was jeopardizing the health of animals, including humans. Although some of its conclusions have been disproven, the book is often credited with sparking the modern environmental movement. The title of the book was inspired by the last line in the John Keats poem 'La Belle Dame sans Merci':

'The sedge is wither'd from the lake, And no birds sing.'

Thirty years after the publication of 'A Silent Spring', a Danish group led by Skakkebaek $^{2}$ reported in a meta-analysis that the mean sperm counts had declined by nearly $50 \%$ worldwide during the previous five decades. They also reported an increase in testicular cancer, hypospadias and cryptorchidism and hypothesized that environmental factors were affecting male gonadal function worldwide. In a follow-up

Department of Medicine, University of Washington, Seattle, WA 98195, USA

Correspondence: Dr BD Anawalt (banawalt@medicine. washington.edu)

Received: 23 October 2012; Revised: 14 November 2012; Accepted: 16 November 2012; Published online: 21 January 2013 article in 1993, Sharpe and Skakkebaek ${ }^{3}$ argued that increased exposure to estrogens via prescription drugs, dietary phytoestrogens and man-made estrogenic chemical pollutants (including pesticides) was the cause of falling global average sperm counts in men. They hypothesized that excessive exposure to these estrogens early in life was disrupting prepubertal Sertoli cell multiplication and resulting in a smaller number of Sertoli cells in adulthood. Because of the stoichiometric relationship between the Sertoli cells necessary to maintain germ cell development, a smaller number of Sertoli cells results in decreased spermatogenesis.

Similar to Carson's 'A Silent Spring', these articles created quite a sensation. Since their publication, there has been considerable controversy about whether global spermatogenesis and therefore male fertility is declining. The Carlsen meta-analysis has been criticized for inappropriate statistical methods, skewed data and failure to control for key variables, ${ }^{4-8}$ but the controversy generated enthusiasm and resources for a number of important studies investigating the possibility that male fertility was in jeopardy from environmental estrogens. The controversies include the following:

1. Is there really a secular decline in human sperm counts?

2. Is the sperm count a meaningful marker for male fertility?

3. Is there a meaningful decline in male fertility?

4. Do man-made chemicals with estrogenic properties represent a danger to the health of men?

\section{GLOBAL SECULAR TRENDS IN SPERM COUNTS}

Since the 'seminal' work of Sharpe and Skakkebaek, there have been many studies examining secular trends of sperm counts and concentrations in different regions of the world. The results have been mixed. There have been several studies confirming the Carlsen meta-analysis. ${ }^{9-17}$ However, there have been many more studies (with many more total subjects enrolled) that show no change or even increased sperm counts. ${ }^{18-36}$ The potential explanations for the variable results in these studies include selection bias of the volunteer subjects, methodological problems with obtaining samples of geographical heterogeneity, variability in age and health, and potential environmental confounders. ${ }^{37}$ Selection bias of volunteer subjects is likely to contribute to significant variability. Volunteer subjects who are willing to donate samples for semen quality studies are likely to have some anxiety or curiosity about their current or future fertility. Many of these men might have some legitimate reason for concern about reproductive dysfunction. As a result, volunteers for semen quality studies might not represent the general population. Methodology can also account for variable results. Sperm counts vary with time of abstinence from last ejaculation and with the season of obtaining the sample. Geographical heterogeneity contributes to variable results in semen quality studies because studies conducted in one region might recruit a cohort that is very different than the general population. Differences in diet, alcohol and tobacco use, drug abuse, overall health, exercise patterns, occupation, as well as differential genetic backgrounds, can all contribute to significant variation in seminal fluid and sperm parameter values. ${ }^{37,38}$ Variability in the mean age of a cohort is important if there are many men over age 50 because there is a modest effect of aging on sperm quality. Overall health has significant effects on the male gonadal axis 
and reproductive function. Poor health and systemic disease are associated with suppression of the gonadal axis and decreased spermatogenesis. Recruitment of a volunteer cohort in a region with relatively poor health compared to other regions could lead to substantial differences in semen quality studies.

On the basis of the conflicting results of studies to date, it is difficult to make any firm conclusions about whether there is a global trend toward decreased average sperm counts in humans. Nonetheless, if there is a downward trend in global average human sperm counts, it is likely to be very modest.

\section{SPERM COUNTS AS A MARKER OF MALE FERTILITY}

In the Carlsen meta-analysis, the authors reported that sperm concentrations declined from 113 million to 66 million per $\mathrm{ml}$ and seminal fluid volumes declined from 3.4 to $2.75 \mathrm{ml}$ over approximately 50 years. These changes appear impressive, but it is unclear whether such a decline in average sperm counts would translate into a significant decline in fertility.

Sperm count as a marker for fertility is problematic. For a couple with known reproductive dysfunction, a low sperm count in the man is a useful indicator of a male factor in the infertile couple. On the other hand, an infertile man with hypogonadotropic hypogonadism and azoospermia often becomes fertile at very low sperm concentrations during gonadotropin replacement therapy. ${ }^{39} \mathrm{It}$ is also clear that many normal men are fertile with sperm counts far below the average levels found in the Carlsen meta-analysis. ${ }^{40}$

Since the publication of the Carlsen metaanalysis, the World Health Organization (WHO) reference values for semen characteristics have been changed twice. Most recently, in 2010, the WHO reference value for sperm counts was decreased from $\geqslant 20$ million to 15 million per $\mathrm{ml}^{40}$ The seminal fluid reference range was also decreased from $\geqslant 2$ to $\geqslant 1.5 \mathrm{ml}$. These 2010 WHO reference values were based on the 5 th percentile of samples obtained from nearly 2000 men in five countries. ${ }^{41}$ The WHO investigators only included men who were known to have fathered a child within the 12-month period before voluntarily providing a sample. The $2010 \mathrm{WHO}$ reference values were lower than previous WHO reference values in part because the former values were based on cohorts without such strict inclusion criteria for normal, fertile men.

The Carlsen meta-analysis included 'unselected, healthy men' with unproven fertility and therefore undoubtedly included subfertile and infertile men with lower sperm counts. It would be expected that the Carlsen meta-analysis would yield lower sperm concentrations and counts than the 2010 WHO reference cohort. However, the 50th percentile sperm concentration for the $2010 \mathrm{WHO}$ reference cohort was 73 million per $\mathrm{ml}$, a number remarkably similar to the 1992 Carlsen meta-analysis 'nadir' value of 66 million per ml. Assuming that the Carlsen meta-analysis is correct in its conclusion that sperm concentrations fell between the 1930s and 1980s, it still appears unlikely that male fertility was compromised significantly worldwide.

In summary, sperm counts are poor markers of male fertility in general. Although very low sperm counts $(<15$ million per $\mathrm{ml} ;<5$ th percentile of the 2010 WHO cohort) might be associated with lower fertility, variations in sperm counts near the median for the 2010 WHO reference cohort are unlikely to be clinically significant.

\section{TRENDS IN MALE REPRODUCTIVE FUNCTION IN MEN}

Whether there are endocrine disruptors causing worldwide decreases in sperm production is not the most important question. The clinically important outcome is whether male fertility is decreasing. There are few convincing data that men have become less capable of reproducing during the last century. In 1992, the world population was about 5.5 billion. In 2012, the world population exceeded 7 billion. ${ }^{42}$ Most of this population increase occurred in poorer, densely populated countries where industrial effluent is poorly regulated or unregulated. For example, the Ganges delta region in India and Bangladesh has a rapidly growing population and is one of the most densely populated areas of the world. The Ganges River and its tributaries contain some of the most polluted water in the world. These pollutants include a variety of industrial solvents and by-products including biphenyls and other compounds postulated to be estrogenic endocrine disruptors. ${ }^{43,44}$ The substantial increase in world population, particularly in regions exposed to high concentrations of potential estrogenic pollutants, argues strongly against a deleterious effect of these pollutants on male fertility.

In wealthier regions of the world, men and women are choosing to have fewer children and delaying attempts at having children. This secular trend confounds attempts to assess male fertility because it is difficult to determine whether decreasing conception rates are due to choice or declining fertility.
In addition, because fertility is known to decline in women after age $30,{ }^{45}$ decreased conception rates in wealthier regions might be due to decreasing female fertility (due to older age at time of attempted conception) and not decreasing male fertility.

\section{POTENTIAL DELETERIOUS EFFECTS OF PHYTOESTROGENS AND ENVIRONMENTAL POLLUTANTS WITH ESTROGENIC PROPERTIES}

Sharpe and Skakkebaek posited that manmade environmental pollutants, as well as phytoestrogens, could have significantly deleterious effects on human male reproduction. This hypothesis has scientific plausibility. Indeed, there is compelling evidence that reptilian, amphibian and fish species have been victims of environmental estrogenic pollutants. ${ }^{46}$ There is now an entire field of science devoted to investigating endocrine disruptors, naturally occurring or synthetic compounds in the environment that disrupt normal endocrine function.

In humans, it is clear that in utero exposure to certain endocrine disruptors has significant adverse effects. The most famous example of a human endocrine disruptor is diethylstilbestrol, a synthetic estrogen that was used to treat nausea during the first trimester of pregnancy. Diethylstilbestrol has been associated with increased reproductive tract abnormalities in boys and vaginal adenocarcinoma in girls exposed to the drug in utero.

However, diethylstilbestrol was a drug administered to pregnant women. The data linking specific environmental pollutants and contaminants to reproductive tract abnormalities are tenuous. In the 2009 Endocrine Society Scientific Statement on Endocrine Disruptors, the authors list several compounds with estrogenic activity that might cause male reproductive tract disorders (including cryptorchidism, testicular cancer and decreased spermatogenesis), but they acknowledge that the epidemiological data relating male reproductive tract disorders to environmental disruptors are indirect and that there is no direct evidence of endocrine disruptors' involvement in the pathogenesis of male reproductive tract disorders in men. ${ }^{44}$

Twenty years after Sharpe and Skakkebaek published their hypothesis, it remains unproven. The data to support the claim remain inferential and weak. However, their hypothesis has had the important effect of awakening the scientific community and the general public to the fact that many 
man-made compounds have sex steroid hormone properties that could adversely affect the health of men. As a result, there is now important research being conducted on some of the most ubiquitous candidate endocrine disruptors that could affect men: phthalates and bisphenol A (commonly used in plastic items), biphenyls (found in industrial solvents), vinclozolin (a fungicide) and many other industrial substances. ${ }^{44,46}$

There remains a vast sea of ignorance about the effects of commonly used drugs and their effects on the male reproductive system. There is no systematic approach to studying the long-term effects of prescription drugs. Worldwide, national regulatory agencies charged with reviewing applications for new drugs routinely approve the use of these drugs with minimal or no safety data about the effects on male reproductive function.

\section{MODERN THREATS TO MALE FERTILITY}

Twenty years after the publication of the Carlsen meta-analysis, it appears unlikely that male fertility is acutely declining. However, there are many threats to male reproductive function that should not be ignored. Paradoxically, obesity and malnutrition are increasing worldwide, and both are associated with decreased male reproductive function. ${ }^{4-49}$ Access to unpolluted drinking water is in jeopardy in large swaths of the world, particularly in developing countries. In developing countries, it is estimated that $70 \%$ of all industrial pollutants are dumped untreated into the water supply. ${ }^{50}$ It is unknown how these pollutants affect human male fertility, but there is biological plausibility that many man-made industrial pollutants might adversely affect human male fertility. Although the data regarding the adverse effects of estrogen disruptors are currently unconvincing, it is possible that further research of specific compounds will demonstrate significant threats to male reproductive function. Finally, conflict over scarce essential resources including water, arable land, minerals and energy sources has led to war and internecine strife worldwide. War kills a disproportionate number of boys and young men who would be tomorrow's fathers. Together, these threats to male fertility are significant.

\section{CONCLUSION}

The Carlsen meta-analysis was flawed and its conclusions were wrong. The SharpeSkakkebaek hypothesis is unproven. However, much like Carson's 'A Silent Spring', the most important outcome is not whether this hypothesis is right or wrong. Both publications raised the scientific and general community's awareness of male reproductive health and spurred important scientific studies on the epidemiology and pathogenesis of male reproductive dysfunction. These papers served as sirens of warning about the potential perils of widespread man-made chemical pollutants. From the onset of the industrial age, we have been cavalier about the use and disposal of many new chemical compounds. They are now ubiquitous. It is likely that some of them are harmful to male human reproductive health, an area of scientific inquiry that was largely ignored until Sharpe and Skakkebaek's article in 1993.

The scientific community must vigorously advocate for the importance of basic scientific studies of the effects of man-made compounds that might act as endocrine disruptors and adversely affect male reproductive health. In addition, there must be an international effort, led by the governments of affluent developed countries, to develop more vigorous research on the safety of drugs on male reproductive function and health. Assessment of the effects on the male gonadal axis and spermatogenesis should be considered compulsory before the approval of new drugs. An international registry should be created that includes any emerging data on the adverse effects of drugs, including any effects on the male reproductive function. Because the effects on male reproductive function might not manifest for years or until the next generation, it should be compulsory to perform postmarketing scientific surveys of prescription and non-prescription drugs. Finally, it is essential that all studies of semen quality and quantity use rigorous methodology. The European Society of Human Reproduction and Embryology has just published a comprehensive and sensible guideline for the design of scientifically rigorous semen quality studies. ${ }^{37}$

The Carlsen paper is 'The Last Spring' for male reproductive health. The penultimate and less famous line of the 'La Belle Dame Sans Merci' should inspire outstanding scientific research on the effects of man-made environmental pollutants on the quality and quantity of spermatogenesis:

\section{'And this is why I sojourn here} Alone and palely loitering'

1 Carson R. A silent spring. Boston: Houghton Mifflin; 1962.

2 Carlsen E, Giwercman A, Keiding N, Skakkebaek NE. Evidence for decreasing quality of semen during past 50 years. BMJ 1992; 305: 609-13.
3 Sharpe RM, Skakkebaek NR. Are oestrogens involved in falling sperm counts and disorders of the male reproductive tract? Lancet 1993; 341: 1362-5.

4 Bromwich P, Cohen J, Stewart I, Walker A. Decline in sperm counts: an artefact of changed reference range of 'normal'? BMJ 1994; 309: 19-22.

5 Farrow S. Falling sperm quality: fact or fiction. $B M J$ 1994; 309: 1-2.

6 Becker S, Berhane K. A meta-analysis of 61 sperm count studies revisited. Fertil Steril 1997; 51: 86-8.

7 Fisch H, Goluboff E. Geographic variations in sperm counts: a potential cause of bias in studies of semen quality. Fertil Steril 1996; 65: 1044-6.

8 Fisch $\mathrm{H}$. Declining sperm counts worldwide; disproving a myth. Urol Clin N Am 2008; 35: 136-47.

9 Adamopoulos DA, Pappa A, Nicopoulou S, Andreou E, Karamertzanis $\mathrm{M}$ et al. Seminal volume and total sperm number trends in men attending subfertility clinics in the greater Athens area during the period 1977-1993. 1996; 11: 1936-41.

10 Almagor M, Ivnitzki I, Yaffe H, Baras M. Changes in semen quality in Jerusalem between 1990 and 2000: a cross-sectional and longitudinal study. Arch Androl 2003; 49: 139-44.

11 Adamopoulos DA, Pappa A, Nicopoulou S, Adreou E, Karamertzanis $\mathrm{M}$ et al. Seminal volume and total sperm number trends in men attending subfertility clinics in the Greater Athens area during the period 1977-1993. Hum Reprod 1996; 11: 1936-41.

12 Auger J, Kunstmann JM, Czyglik F, Jouannet $P$. Decline in semen quality among fertile men in Paris during the past 20 years. N Engl J Med 1995; 332 : 281-5.

13 Bilotta P, Guglielmo R, Steffe M. Analysis of decline in seminal fluid in the Italian population during the past 15 years. Minerva Ginecol 1999; 51: 223-31. Italian.

14 Bonde JP, Kold Jensen T, Brixen Larsen S, Abell A, Scheike $T$ et al. Year of birth and sperm count in 10 Danish occupational studies. Scand J Work Environ Health 1998; 24: 407-13.

15 Gopalkrishnan K. Characteristics of semen parameters in a selected population of Indian men over a period of 10 years. Curr Sci 1998; 75: 939-40.

16 Irvine S, Cawood E, Richardson D, MacDonald E, Aitken J. Evidence of deteriorating semen quality in the United Kingdom: birth cohort study in 577 men in Scotland over 11 years. BMJ 1996; 312: 467-71.

17 Menchini-Fabris F, Rossi P, Palego P, Simi S, Turchi $P$. Declining sperm counts in Italy during the past 20 years. Andrologia 1996; 28: 304.

18 Acacio BD, Gottfried T, Israel R, Sokol RZ. Evaluation of a large cohort of men presenting for a screening semen analysis. Fertil Steril 2000; 73: 595-7.

19 Andolz P, Bielsa MA, Vila J. Evolution of semen quality in North-eastern Spain: a study in 22,759 infertile men over a 36 year period. Hum Reprod 1999; 14: 731-5.

20 Benshushan A, Shoshani O, Paltiel O, Schenker JG, Lewin $A$. Is there really a decrease in sperm parameters among healthy young men? A survey of sperm donations during 15 years. J Assist Reprod Genet 1997; 14: 347-53.

21 Berling S, Wolner-Hanssen P. No evidence of deteriorating semen quality among men in infertile relationships during the last decade: a study of males from Southern Sweden. Hum Reprod 1997; 12: 1002-5.

22 Bujan L, Mansat A, Pontonnier F, Mieusset R. Time series analysis of sperm concentration in fertile men in Toulouse, France between 1977 and 1992. BMJ 1996; 312: 471-2.

23 Dama MS, Rajender S. Secular changes in the semen quality in India during the past 33 years. J Androl 2012; 33: 740-4.

24 Emanuel E, Goluboff E, Fisch H. MacLeod revisited: sperm count distributions in 374 fertile men from 1971 to 1994 . Urology 1998; 51: 86-8.

25 Fisch H, Goluboff ET, Olson JH, Feldshuh J, Broder SJ et al. Semen analyses in 1,283 men from the United States over a 25 -year period: no decline in quality. Fertil Steril 1996; 65: 1009-14. 
Man-made pollution as a threat to male fertility

BD Anawalt

168

26 Gyllenborg J, Skakkebaek NE, Nielsen NC, Keiding N, Giwercman A. Secular and seasonal changes in semen quality among young Danish men: a statistical analysis of semen samples from 1927 donor candidates during 1977-1995. Int J Androl 1999; 22: 28-36.

27 Handelsman DJ. Sperm output of healthy men in Australia: magnitude of bias due to self-selected volunteers. Hum Reprod 1997; 12: 2701-5.

28 Itch N, Kayama F, Tatsuki TJ, Tsukamoto T. Have sperm counts deteriorated over the past 20 years in healthy, young Japanese men? Results from the Sapporo area. J Androl 2001; 22: 40-4.

29 Marimuthu P, Kapilashrami MC, Misro MM, Singh G. Evaluation of trend in semen analysis for 11 years in subjects attending a fertility clinic in India. Asian J Androl 2003; 5: 221-5.

30 Mukhopadhyay D, Varghese AC, Pal M, Banerjee SK, Bhattacharyya AK et al. Semen quality and agespecific changes: a study between two decades on 3,729 male partners of couples with normal sperm count and attending an andrology laboratory for infertility-related problems in an Indian city. Fertil Steril 2010; 93: 2247-54.

31 Paulsen CA, Burman NG, Wang C. Data from men in greater Seattle area reveals no downward trend in semen quality: further evidence that deterioration of semen quality is not geographically uniform. Fertil Steril 1996; 65: 1015-20.

32 Rasmussen PE, Erb K, Westergaard LG, Lauren SB. No evidence for decreasing semen quality in four birth cohorts of 1,055 Danish men born between 1950 and 1970. Fertil Steril 1997; 68: 1059-64.
33 See JT, Rh KH, Park YS, Lee MS. Semen quality over a 10-year period in 22,249 men in Korea. Int J Androl 2000; 23: 194-8.

34 Vierula M, Niemi M, Keiski A, Saaranen M, Saarikoski $S$ et al. High and unchanged sperm counts of Finnish men. Int J Androl 1996; 19: 11-7.

35 Younglai EV, Collins JA, Foster WG. Canadian semen quality: an analysis of sperm density among eleven academic fertility centers. Fertil Steril 1998; 70: 76-80.

36 Zorn B, Virant-Klun I, Verdenik I, Meden-Vrtovec H. Semen quality changes among 2343 healthy Slovenian men included in an IVF-ET programme from 1983 to 1996. Int J Androl 1999; 22: 178-83.

37 Sánchez-Pozo MC, Mendiola J, Serrano M, Mozas J, Björndahl $L$ et al. Proposal of guidelines for the appraisal of SEMen QUAlity studies (SEMQUA). Hum Reprod 2013; 28: 10-21.

38 Larsen SB, Abell A, Bonce JP. Selection bias in occupational sperm studies. Am J Epidemiol 1998; 147: 681-5.

39 Li P, Gordon Baker HW, Jayadev V, Zacharin M, Conway AJ et al. Induction of spermatogenesis and fertility during gonadotropin treatment of gonadotropin-deficient infertile men: predictors of fertility outcome. J Chin Endocrinol Metal 2009; 94: 801-8.

40 Cooper TG, Honan E, won Eckardstein S, Auger J, Baker HW et al. World Health Organization reference values for human semen characteristics. Hum Reprod Update 2010; 16: 231-45.

41 Esteves SC, Zuni A, Aziz N, Alvarez JG, Sabanegh ES Jr et al. Critical appraisal of World Health Organization's new reference values for human semen characteristics and effect on diagnosis and treatment of subfertile men. Urology 2012; 79: 16-22.

42 Bloom DE. 7 billion and counting. Science 2011; 333: 562-9.

43 Senthilkumar K, Kennan K, Sinha RK, Tanabe S, Giesy JP. Bioaccumulation profiles of polychlorinated biphenyl congeners and organochlorine pesticides in Ganges River dolphins. Environ Toxicol Chem 1999; 18: 1511-20.

44 Diamanti-Kandarakis E, Bourguignon JP, Giudice LC, Hawser R, Prins GS et al. Endocrine-disrupting chemcoals: an Endocrine Society Scientific Statement. Endocr Rev 2009; 30: 293-342.

45 Kimberly L, Case A, Cheung AP, Sierra S, AIAsiri S et al. Advanced reproductive age and fertility. Int J Gynaecol Obstet 2012; 117: 95-102.

46 Aitken RJ, Koopman P, Lewis SE. Seeds of concern. Nature 2004; 432: 48-52.

47 Res LO, Dias FG. Male fertility, obesity, and bariatric surgery. Reprod Sci 2012; 19: 778-85.

48 Hofstra J, Loves S, van Wageningen B, RuinemansKoerts J, Jansen I et al. High prevalence of hypogonadotropic hypogonadism in men referred for obesity treatment. Neth J Med 2008; 66: $103-$ 9.

49 Teerds KJ, de Rooij DG, Keijer J. Functional relationship between obesity and male reproduction: from humans to animal models. Hum Reprod Update 2011; 17: 667-83.

50 http://www.unwater.org/statistics_pollu.html (accessed 15 October 2012).

Asian Journal of Andrology 